\title{
Tall cell carcinoma of the breast with reverse polarity: case report with gene sequencing and literature review
}

\author{
Xiaohui Zhang ${ }^{1 \#}$, Huanwen Wu ${ }^{2 \#}$, Zhe Wang, Yidong Zhou ${ }^{1}$, Feng Mao ${ }^{1}$, Yan Lin $^{1}$, Songjie Shen ${ }^{1}$, \\ Zhiyong Liang ${ }^{2}$, Qiang Sun ${ }^{1}$ \\ ${ }^{1}$ Department of Breast Surgery, Peking Union Medical College Hospital, Chinese Academy of Medical Sciences, and Peking Union Medical College, \\ Beijing, China; ${ }^{2}$ Department of Pathology, Peking Union Medical College Hospital, Chinese Academy of Medical Sciences, and Peking Union \\ Medical College, Beijing, China \\ "These authors contributed equally to this work. \\ Correspondence to: Qiang Sun. Department of Breast Surgery, Peking Union Medical College Hospital, Chinese Academy of Medical Sciences, and \\ Peking Union Medical College, no. 1 Shuaifuyuan, Dongcheng District, Beijing 100730, China. Email: sunqpumch@163.com.
}

\begin{abstract}
Tall cell carcinoma of the breast with reverse polarity (TCCRP), described firstly and also known as tall cell variant of papillary breast carcinoma (TCVPBC), is a rare type of breast cancer that mimics papillary thyroid carcinoma (PTC) histopathologically. As the incidence of this type of tumor is very low, awareness of it is crucial to ensuring that unnecessary clinical investigations are avoided. The present study examined a 45-year-old woman in China who was diagnosed with TCCRP. This paper outlines her demographic and clinicopathologic data, and her follow-up and immunohistochemical examination results. Furthermore, this study used the next-generation sequencing (NGS) technique to identify concurrent isocitrate dehydrogenase 2 (IDH2) and phosphatidylinositol 3-kinase catalytic alpha (PIK3CA) hotspot mutations. Notably, the novel results of the study showed that the IDH2 R120 (rather than the IDH2 R172) mutation may also be present in this disease. Additionally, a comprehensive literature review was conducted to elucidate some of the significant clinical and pathological features of this type of disease. This information may provide important insights that can be used in diagnosis and treatment. It is essential both for physicians and pathologists to recognize the existence of TCCRP, with its own specific clinical and pathological characteristics. Further research using molecular biology techniques should be conducted in the future to characterize this unique entity.
\end{abstract}

Keywords: Tall cell carcinoma with reverse polarity (TCCRP); breast cancer; IDH2 mutation; next-generation sequencing (NGS); case report

Submitted Sep 02, 2020. Accepted for publication Dec 05, 2020.

doi: $10.21037 /$ gs-20-695

View this article at: http://dx.doi.org/10.21037/gs-20-695

\section{Introduction}

Tall cell carcinoma of the breast with reverse polarity (TCCRP), also known as the tall cell variant of papillary breast carcinoma (TCVPBC), is a rare histological type of breast cancer that resembles the tall cell variant of papillary thyroid carcinoma (PTC) in morphology. Although its pathological diagnosis may be challenging, its prognosis is generally favorable. Since 2003, when Eusebi et al. described the first five cases and denominated as the breast tumor resembled the tall cell variant of papillary thyroid carcinoma (BTRPTC) (1), several cases have been reported by different institutions around the world over the past 17 years. Due to the featured morphological characteristics of the papillary structures lined by eosinophilic columnar mitochondrion-rich cells with nuclear grooves and nuclear pseudo-inclusions, TCCRP is easily to be associated with PTC, as the breast is not an uncommon site for metastasis, and about $5 \%$ of all such cases originate in the thyroid. However, neither the results of the immunohistochemical markers related to the 

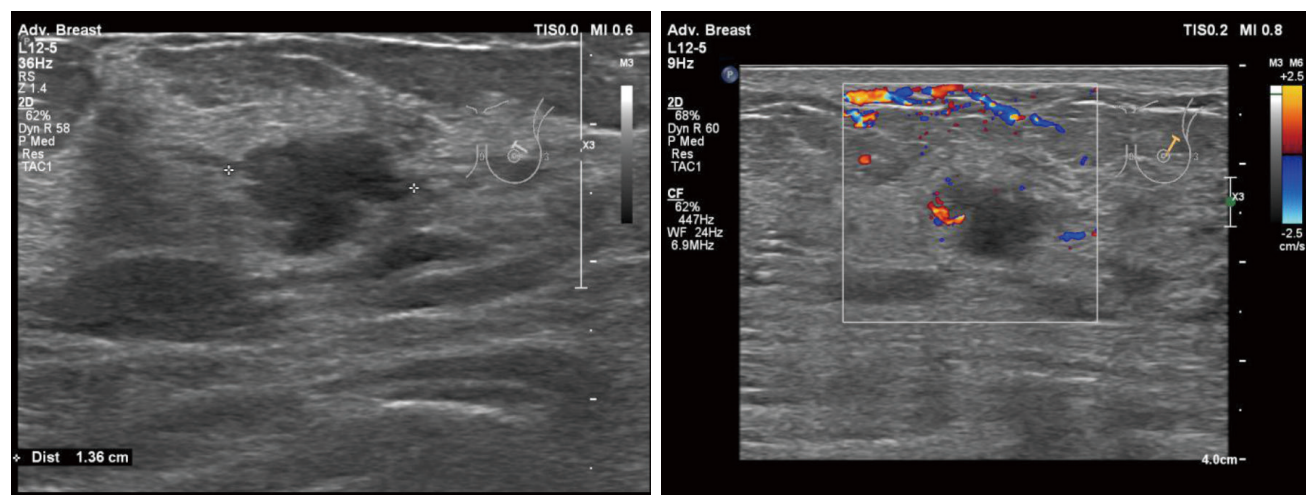

Figure 1 Mammary ultrasound examination results.

thyroid origin nor the genetic evidence (e.g., RET/PTC rearrangements and BRAF mutations), which may produce the morphological expression supporting the connection between this disease and thyroid tumor. Thus, Masood et al. proposed that the terminology should be changed from "breast tumor resembling the tall cell variant of papillary thyroid carcinoma" to "tall cell variant of papillary breast carcinoma" to prevent unnecessary relevant studies being conducted that sought to exclude the association of this lesion with PTC (2). In 2016, Chiang et al. redefined the tumor as a discrete subtype of breast carcinoma, the solid papillary carcinoma with reverse polarity (SPCRP), based on its unique histologic and genetic properties (3). In 2019, this type of disease, referred to as TCCRP, was recognized as a separate entity in the 5th edition of the World Health Organization (WHO) series on the classification of breast tumors. The population of breast cancer patients in China is large and increasing gradually; however, to date, no report appears to have been published on the rare disease of TCCRP. In this paper, we report on the first case diagnosed as TCCRP in China, and show the characteristic morphologic, immunohistochemical and molecular features of this disease. We also use next-generation sequencing (NGS) to analyze its genetic mutations, and to confirm the presence of specific hotspot mutations (IDH2 and PIK3CA).

We present the following case in accordance with the CARE reporting checklist (available at http://dx.doi. org/10.21037/gs-20-695.

\section{Case presentation}

This study examined a 45-year-old Chinese woman who had a gradually enlarged left breast mass for 2 years before being diagnosed in August in 2019. She had no prior history of cancer. On physical examination, the tumor was found to be located in the upper outside quadrant of the left breast. A mammary ultrasonography showed that a hypoechoic area of $1.0 \times 1.2 \times 1.2 \mathrm{~cm}^{3}$ in size at 2 o'clock, with an irregular shape, unclear boundary, blood flow signals at the periphery, and category $4 \mathrm{C}$ rating under the Breast Imaging Reporting and Database System (BI-RADS) (Figure 1). The mammography revealed a disorganized glandular structure tumor rating category 4 under the BI-RADS (Figure 2). The patient underwent wide local excision and sentinel lymph node biopsy (SLNB) as treatment.

Postoperative paraffin pathology confirmed the diagnosis of TCCRP with a maximum diameter of $1.0 \mathrm{~cm}$ and negative for sentinel lymph nodes (0/6). Histologically, circumscribed tumor cell nests were found with fibrovascular cores infiltrating between the normal ducts. The fibrovascular cores contained aggregates of foamy histiocytes. The columnar tumor cells demonstrated abundant eosinophilic cytoplasm and mild nuclear atypia (see Figure $3 A, B$ ). The nuclei were centralized or located at the top of the cytoplasm (inverted), and mitosis was rare. Nucleus elongation, nuclear clearing, nuclear grooving, and intranuclear pseudo-inclusions were easy to find (see Figure 3C,D).

The immunohistochemical results showed that the tumor cells were negative for ER, PR, HER-2, S-100, TTF-1, Thy, CgA, Syn, and p53, but showed positivity with variable extent and intensity for AR, CK5/6, GATA3, GCDFP-15 and, Mammaglobin. The Ki-67 proliferative index was low (5\%). Both p63 and CK14 immunostaining showed an absence of myoepithelial cells around and within the tumor nests (see Figure 3E,F,G,H). GCDFP-15 and mammaglobin were both positive, indicating that the tumor originated from the breast tissue. Additionally, as 

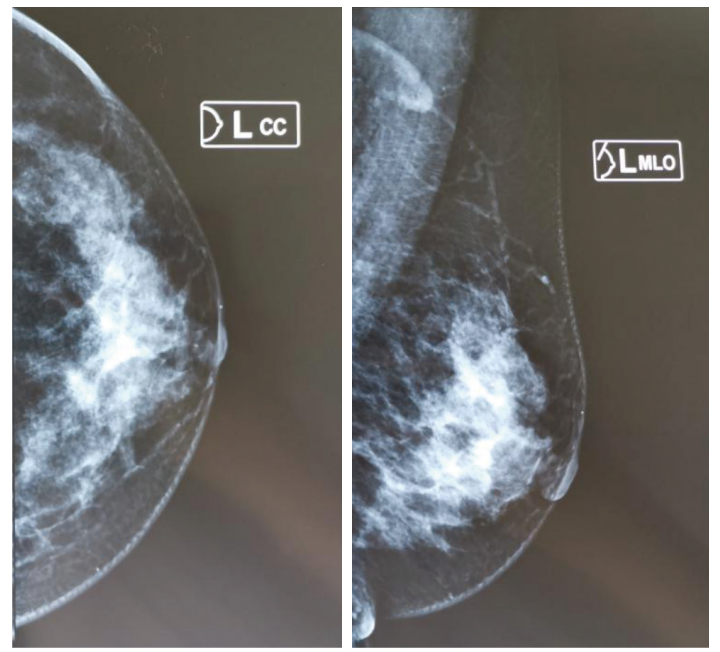

Figure 2 Mammography examination results.

both TTF-1 and Thy were negative, this helped to rule out thyroid cancer distant metastasis. Furthermore, no significant abnormality was found in the thyroid ultrasound examination. A molecular genetic analysis using targeted NGS was conducted. The result showed concurrent IDH2 hotspot mutation (p.R120G) and PIK3CA hotspot mutation (p.H1047R) (Figure 4).

All of the procedures performed in this studies involving the human participants were conducted in accordance with the ethical standards of the relevant institutional and/ or national research committee(s) and with the Helsinki Declaration (as revised in 2013). Written informed consent was obtained from the patient.

\section{Discussion}

As the incidence of TCCRP is low, it is difficult to conduct a valuable retrospective analysis of the disease from independent case reports or small-scale cohort studies. However, we comprehensively reviewed relevant articles (15 in total) published from 2003 to date, and extracted key information including demographic, clinicopathologic, and immunohistochemical data, along with hotspot gene sequencing results (Tables $\mathrm{S} 1, \mathrm{~S} 2$ ), to detect meaningful patterns by expanding the sample size (1-15). After eliminating the repeated cases from among the abovementioned studies, a total of 74 cases (including this present case) remained. The median age of all patients was 64 years (range, $45-85$ years); patients aged $\geq 60$ accounted for $70.1 \%$ (52/74). The median tumor size was $1.3 \mathrm{~cm}$ (range, $0.6-5.0 \mathrm{~cm})$. Of the tumors, $81.6 \%(58 / 72)$ were smaller than $2 \mathrm{~cm}$. In 42 patients for whom details of the specific operation method were provided, breast-conserving surgeries (BCSs) and mastectomies were performed in 37 cases $(88.1 \%)$ and 5 cases $(11.9 \%)$, respectively. Of the 13 patients who underwent exact axillary surgeries, SLNBs were performed for 9 cases (69.2\%) and axillary lymph node dissections (ALNDs) for 4 cases (30.8\%). However, $90.3 \%$ $(28 / 31)$ of the patients were negative for lymph nodes. In terms of adjuvant therapy, $65.6 \%(21 / 32)$ of patients neither received chemotherapy nor radiotherapy; $54.5 \%$ (6/11) received chemotherapy, and 81.8\% (9/11) received radiotherapy. The median follow-up time was 29 months (range, 3-132 months), at which time 94.1\% (32/34) of patients were alive and well, local recurrence had occurred in 1 patient, and bone metastasis had occurred in 1 patient.

In relation to the immunohistochemistry examinations, $36.1 \%(26 / 72)$ of patients were ER positive, 20\% (12/60) were PR positive, $32.1 \%(17 / 53)$ were AR positive, and $100 \%$ were HER-2 negative (47/47). Further, $66.0 \%$ (31/47) belonged to the triple-negative breast cancer (TNBC) subtype. The proportions of CK $5 / 6$ positive and p63 negative were very high at $90.2 \%(46 / 51)$ and $95 \%$ (57/60), respectively. GCDFP-15 is a protein secreted by the mammary gland epithelium, and is often present in breast cancer. A positive result indicates that the neoplasm originates from breast tissue. Of the patients evaluated, $59.2 \%$ (29/49) were GCDFP-15 positive. The percentages of patients negative for both TTF-1 and Thy negative were $100 \%(54 / 54,36 / 36)$; these results were used to exclude the source of PTC. Notably, very few patients were tested for other immunohistochemical items; thus, the statistical 
A

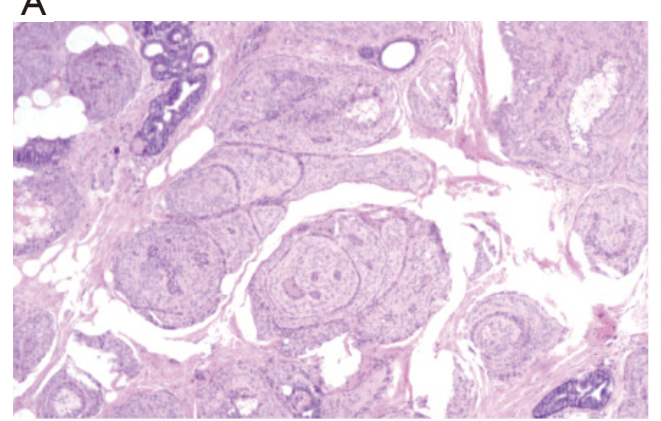

C

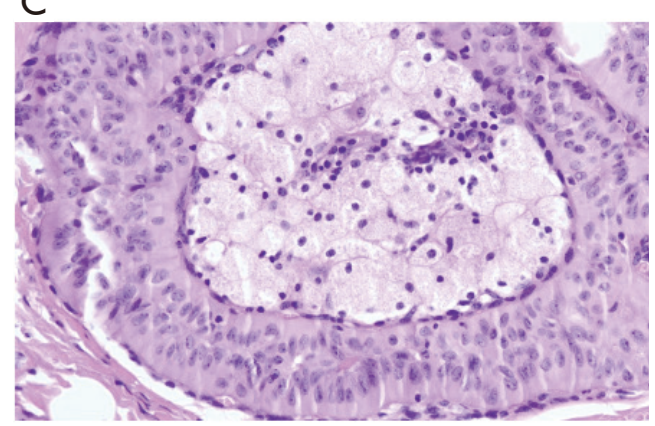

E

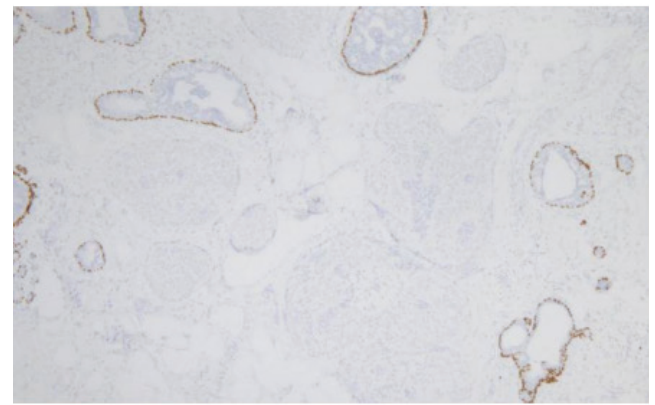

G

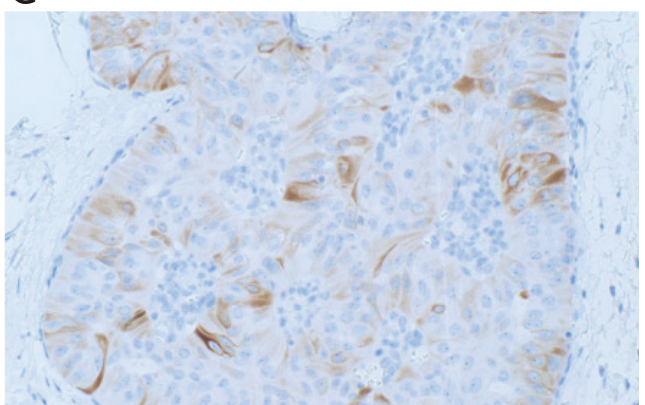

B

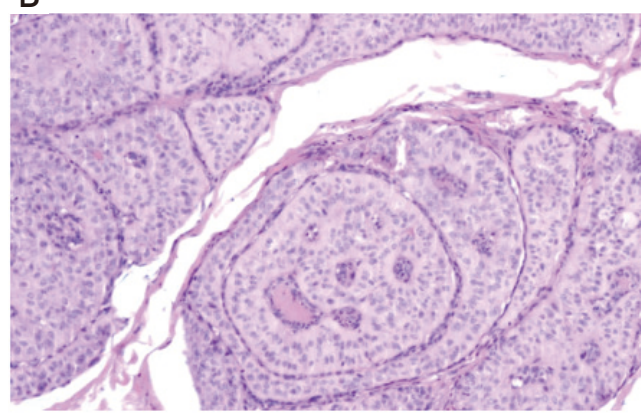

D

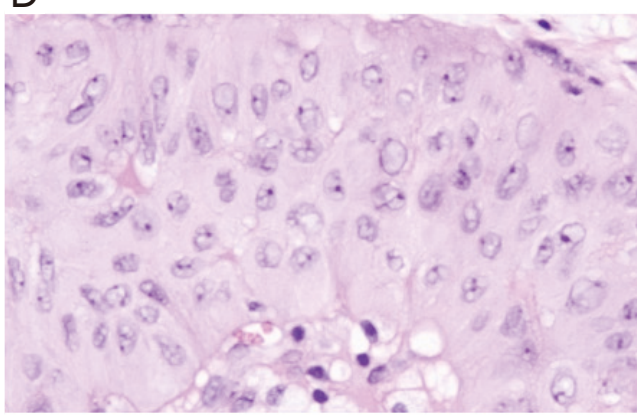

F

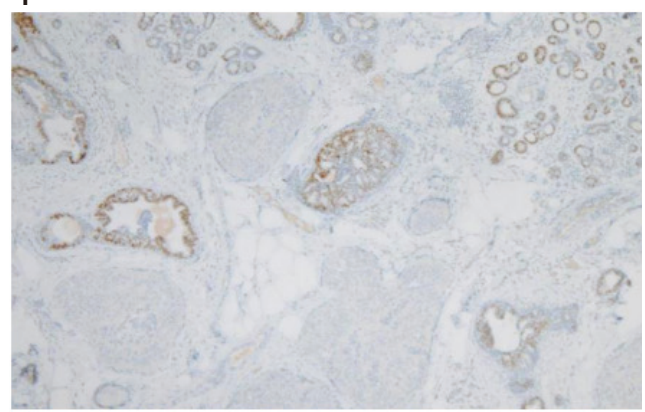

$\mathrm{H}$

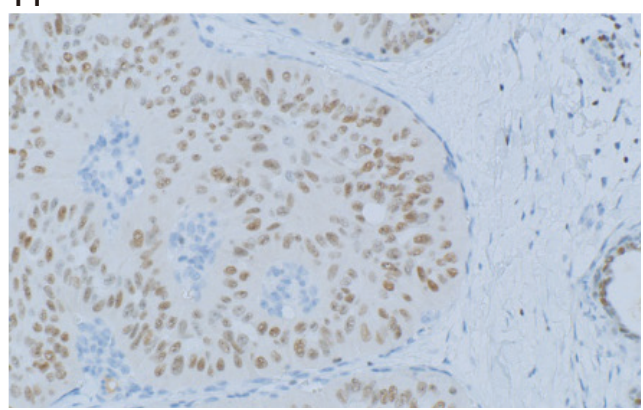

Figure 3 Histopathological features of tall cell carcinoma of the breast with reverse polarity. (H\&E staining; A, $\times 40 ; \mathrm{B}, \times 100$ ) Circumscribed tumor cell nests with fibrovascular cores had infiltrated between normal ducts. Fibrovascular cores contained aggregates of foamy histiocytes. (H\&E staining; C, $\times 200 ; \mathrm{D}, \times 400$ ) Nuclei were centralized or located at the top of the cytoplasm (inverted), and mitosis was rare. Nucleus elongation, nuclear clearing, nuclear grooving, and intranuclear pseudo-inclusions were easy to find. (E, $\times 40)$ p63 immunostaining showed an absence of myoepithelial cells around and within tumor nests. $(F, \times 40)$ Tumor cells were negative for ER staining. $(G, \times 200)$ Tumor cells were positive for $\mathrm{CK} 5 / 6$ staining. $(\mathrm{H}, \times 200)$ Tumor cells were positive for GATA3 staining. ER, estrogen receptor; CK, cytokeratin; GATA3, GATA binding protein 3. 
A

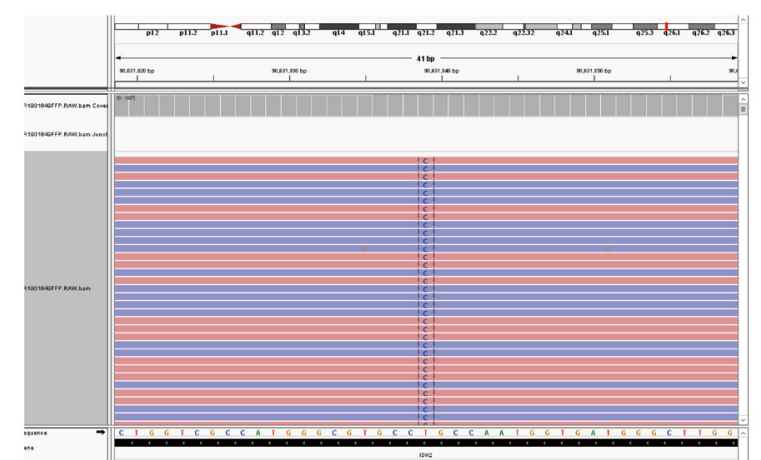

B

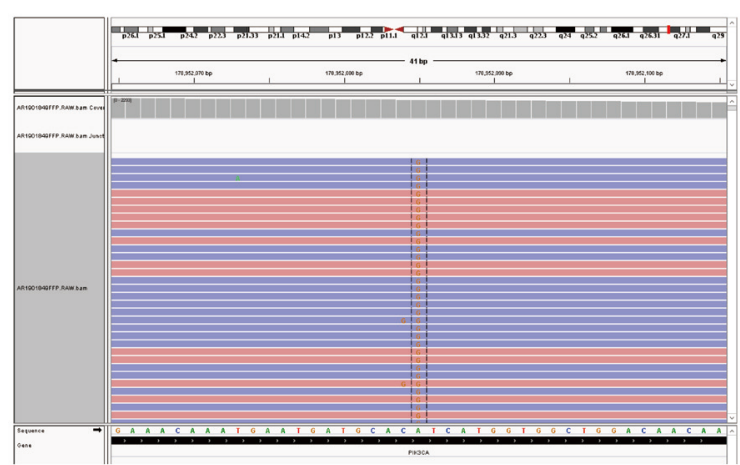

Figure 4 NGS results of the DNA extracted from tumor cells that which revealed concurrent IDH2 and PIK3CA hotspot mutations in our present case. (A) IDH2:c.358A>G(p.R120G). (B) PIK3CA:c.3140A>G(p.H1047R). NGS, next-generation sequencing; IDH2, isocitrate dehydrogenase 2; PIK3CA, phosphatidylinositol 3-kinase catalytic alpha.

results may not be representative. Of the patients detected for hotspot mutation status, the IDH2 mutation rate was $87.8 \%$ (43/49), while the PIK3CA mutation rate was $67.5 \%$ (27/40), and the proportion of both mutations was $60 \%$ (24/40).

Based on the above statistics analysis, our analysis revealed that this type of tumor was more common in elderly women. Patients usually received BCSs, and SLNBs were often carried out indicating a low rate of lymph node metastasis. Chemotherapy and radiotherapy were not often used in postoperative adjuvant therapy, but patients could also have a good prognosis. The TNBC subtype proportion was significantly higher than that of other types. Nearly $90 \%$ of the patients harbored the IDH 2 mutation, and $60 \%$ harbored the concomitant PIK3CA mutation.

Papillary tumors of the breast are diagnostically challenging lesions and represent a wide spectrum of diseases from papilloma to invasive papillary carcinoma (PC) (16). In support of the notion that TCCRP is a variant of PC, Hameed et al. showed that these unique cytological structure characteristics were not limited to it, and that one or more of them could be also found in some other subtypes of breast PC (17). Conversely, Alsadoun et al., by making comparisons with other benign or malignant breast papillary lesions in the morphologic, immunohistochemical, and molecular profiles, contended that this disease was a singular breast neoplasm that can be distinguished from others (10). In Toss's study, 75 PC of breast cases previously diagnosed in routine practice were reviewed again and compared with 10 TCCRP cases to determine whether TCCRP constitutes a distinct disease or is just a PC variant (18).
Toss concluded that the introduction of this new disease should be accompanied by sufficient evidence for its identification and classification in routine practice. Zhong et al. used the NGS technique to detect the molecular characterization among them, however, as none of the conventional solid PCs demonstrated a IDH2 mutation, Zhong et al. were of the view that the tumor is unique in terms of its histology and molecular profile (13).

Among the 21 types of breast cancer histologic subtypes detailed by the WHO (19), very few genotypephenotype correlations are known to harbor distinct recurrent genetic alterations. TCCRP is the first type of breast cancer to be associated with IDH mutations, which are more commonly detected in glioma, acute myeloid leukemia, chondrosarcoma, and cholangiocarcinoma (20). More researchers have begun to explore the role of IDH mutations in tumorigenesis and progression, and have also begun to propose clinical considerations for the treatment of IDH-mutated tumors based on emerging clinical data from mutant IDH1/2 inhibitor trials. Functional studies conducted by Chiang et al. showed that IDH2 and PIK3CA hotspot mutations are the likely drivers of TCCRP, resulting in its reversed nuclear polarization phenotype, and thus can constitute its molecular definition (3). Lozada et al. reported that high frequencies of IDH2 R172 and PIK3CA hotspot mutations were present in their patient cohort (12). Pareja et al. further demonstrated that the immunohistochemical analysis of IDH2 R172 was highly sensitive and specific for the detection of IDH2 R172 hotspot mutations, and was likely suitable as a diagnostic tool for evaluating the excisions and core needle biopsy 
materials of TCCRP (14). Notably, IDH2 R120, rather than the IDH2 R172 mutation, was detected in our case, a finding that has not been reported in previous studies. Our results indicated that IDH2 mutations in other sites could also exist in TCCRP, and these should be taken into consideration when undertaking immunohistochemical analyses of IDH2.

In summary, this paper reported the first case of TCCRP diagnosed in China. Additionally, a comprehensive literature review was performed to examine some of the significant clinical and pathological features. The results of this review provide in-depth insights into TCCRP that could assist in the diagnosis and treatment of this disease. the diagnosis and treatment of this disease. It is essential that physicians and pathologists recognize that TCCRP may have its own specific clinical and pathological characteristics so that a standardized management approach can be developed. Further research using molecular biology techniques should be conducted in the future to characterize this unique entity.

\section{Acknowledgments}

Funding: None.

\section{Footnote}

Reporting Checklist: The authors have completed the CARE reporting checklist. Available at http://dx.doi.org/10.21037/ gs-20-695

Conflicts of Interest: All the authors have completed the ICMJE uniform disclosure form (available at http://dx.doi. org/10.21037/gs-20-695). The authors have no conflicts of interest to declare.

Ethical Statement: The authors are accountable for all aspects of the work in ensuring that questions related to the accuracy or integrity of any part of the work are appropriately investigated and resolved. All of the procedures performed in studies involving human participants were conducted in accordance with the ethical standards of the relevant institutional and/or national research committee(s) and with the Helsinki Declaration (as revised in 2013). Written informed consent was obtained from the patient.

Open Access Statement: This is an Open Access article distributed in accordance with the Creative Commons Attribution-NonCommercial-NoDerivs 4.0 International License (CC BY-NC-ND 4.0), which permits the noncommercial replication and distribution of the article with the strict proviso that no changes or edits are made and the original work is properly cited (including links to both the formal publication through the relevant DOI and the license). See: https://creativecommons.org/licenses/by-nc-nd/4.0/.

\section{References}

1. Eusebi V, Damiani S, Ellis IO, et al. Breast tumor resembling the tall cell variant of papillary thyroid carcinoma: report of 5 cases. Am J Surg Pathol 2003;27:1114-8.

2. Masood S, Davis C, Kubik MJ. Changing the term "breast tumor resembling the tall cell variant of papillary thyroid carcinoma" to "tall cell variant of papillary breast carcinoma". Adv Anat Pathol 2012;19:108-10.

3. Chiang S, Weigelt B, Wen HC, et al. IDH2 Mutations Define a Unique Subtype of Breast Cancer with Altered Nuclear Polarity. Cancer Res 2016;76:7118-29.

4. Cameselle-Teijeiro J, Abdulkader I, Barreiro-Morandeira $\mathrm{F}$, et al. Breast tumor resembling the tall cell variant of papillary thyroid carcinoma: a case report. Int J Surg Pathol 2006;14:79-84.

5. Tosi AL, Ragazzi M, Asioli S, et al. Breast Tumor Resembling the Tall Cell Variant of Papillary Thyroid Carcinoma: Report of 4 Cases With Evidence of Malignant Potential. Int J Surg Pathol 2007;15:14-9.

6. Chang SY, Fleiszer DM, Mesurolle B, et al. Breast Tumor Resembling the Tall Cell Variant of Papillary Thyroid Carcinoma. Breast J 2009;15:531-5.

7. Colella R, Guerriero A, Giansanti M, et al. An Additional Case of Breast Tumor Resembling the Tall Cell Variant of Papillary Thyroid Carcinoma. Int J Surg Pathol 2015;23:217-20.

8. Bhargava R, Florea AV, Pelmus M, et al. Breast Tumor Resembling Tall Cell Variant of Papillary Thyroid Carcinoma: A Solid Papillary Neoplasm With Characteristic Immunohistochemical Profile and Few Recurrent Mutations. Am J Clin Pathol 2017;147:399-410.

9. Foschini MP, Asioli S, Foreid S, et al. Solid Papillary Breast Carcinomas Resembling the Tall Cell Variant of Papillary Thyroid Neoplasms: A Unique Invasive Tumor With Indolent Behavior. Am J Surg Pathol 2017;41:887-95.

10. Alsadoun N, MacGrogan G, Truntzer C, et al. Solid 
papillary carcinoma with reverse polarity of the breast harbors specific morphologic, immunohistochemical and molecular profile in comparison with other benign or malignant papillary lesions of the breast: a comparative study of 9 additional cases. Mod Pathol 2018;31:1367-80.

11. Gai L, Done SJ, Cook D, et al. Breast tumour resembling tall cell variant of papillary thyroid carcinoma: case presentation (in a patient with Lynch syndrome). J Clin Pathol 2018;71:1031-2.

12. Lozada JR, Basili T, Pareja F, et al. Solid papillary breast carcinomas resembling the tall cell variant of papillary thyroid neoplasms (solid papillary carcinomas with reverse polarity) harbour recurrent mutations affecting IDH2 and PIK3CA: a validation cohort. Histopathology 2018;73:339-44.

13. Zhong E, Scognamiglio T, D'Alfonso T, et al. Breast Tumor Resembling the Tall Cell Variant of Papillary Thyroid Carcinoma: Molecular Characterization by NextGeneration Sequencing and Histopathological Comparison With Tall Cell Papillary Carcinoma of Thyroid. Int J Surg Pathol 2019;27:134-41.

14. Pareja F, da Silva EM, Frosina D, et al. Immunohistochemical analysis of IDH2 R172 hotspot mutations in breast papillary neoplasms: applications in the

Cite this article as: Zhang $\mathrm{X}, \mathrm{Wu} \mathrm{H}$, Wang Z, Zhou Y, Mao F, Lin Y, Shen S, Liang Z, Sun Q. Tall cell carcinoma of the breast with reverse polarity: case report with gene sequencing and literature review. Gland Surg 2021;10(2):837-843. doi: 10.21037/ gs-20-695 diagnosis of tall cell carcinoma with reverse polarity. Mod Pathol 2020;33:1056-64.

15. Haefliger S, Muenst S, Went $P$, et al. Tall cell carcinoma of the breast with reversed polarity (TCCRP) with mutations in the IDH2 and PIK3CA genes: a case report. Mol Biol Rep 2020;47:4917-21.

16. Rakha EA, Ahmed MA, Ellis IO. Papillary carcinoma of the breast: diagnostic agreement and management implications. Histopathology 2016;69:862-70.

17. Hameed O, Perry A, Banerjee R, et al. Papillary Carcinoma of the Breast Lacks Evidence of RET Rearrangements Despite Morphological Similarities to Papillary Thyroid Carcinoma. Mod Pathol 2009;22:1236-42.

18. Toss MS, Billingham K, Egbuniwe IU, et al. Breast Tumours Resembling the Tall Cell Variant of Thyroid Papillary Carcinoma: Are They Part of the Papillary Carcinoma Spectrum or a Distinct Entity? Pathobiology 2019;86:83-91.

19. Lakhani SR, Ellis IO, Schnitt SJ, et al. WHO classification of tumours of the breast. Lyon: IARC Press, 2012.

20. Marotti JD, Schnitt SJ. Genotype-Phenotype Correlations in Breast Cancer. Surg Pathol Clin 2018;11:199-211. 
Supplementary

Table S1 Demographic, clinicopathologic, and follow-up information of patients

\begin{tabular}{|c|c|c|c|c|c|c|c|c|c|}
\hline $\begin{array}{l}\text { Case } \\
\text { No. }\end{array}$ & Source & Age & Site & $\begin{array}{l}\text { Size } \\
(\mathrm{cm})\end{array}$ & $\begin{array}{l}\text { Surgery } \\
\text { Method }\end{array}$ & LN Status & $\begin{array}{l}\text { Adjuvant } \\
\text { Therapy }\end{array}$ & $\begin{array}{r}\text { Follow-up } \\
\text { (months) }\end{array}$ & Outcome \\
\hline 1 & \multirow{5}{*}{$\begin{array}{c}\text { Eusebi } \\
{[5]}\end{array}$} & 58 & L-LIQ & 1.2 & $B C S$ & UK & ND & 26 & Alive and well \\
\hline 2 & & 70 & R-UOQ & 1.3 & $\mathrm{BCS}$ & UK & UK & 54 & Alive and well \\
\hline 3 & & 57 & L-UOQ & 1.6 & BCS & UK & UK & 28 & Alive and well \\
\hline 4 & & 74 & $\mathrm{R}$ & 2.0 & BCS & UK & UK & 108 & Alive and well \\
\hline 5 & & 56 & UK & 0.8 & UK & UK & UK & UK & UK \\
\hline 6 & Teijeiro [1] & 64 & R-LQs & 4.1 & M+ALND & Positive & $C T+R T$ & 32 & Alive with bone metastasis \\
\hline 7 & \multirow[t]{4}{*}{ Tosi [4] } & 80 & R-LOQ & 2.5 & BCS & Positive & ND & 3 & Alive and well \\
\hline 8 & & 45 & $R-U O Q$ & 5.0 & BCS & Negative & UK & 5 & Alive and well \\
\hline 9 & & 61 & $\mathrm{R}$ & 2.0 & $B C S$ & Negative & UK & 8 & Alive and well \\
\hline 10 & & 47 & $\mathrm{R}$ & 2.3 & BCS & Negative & UK & 10 & Alive and well \\
\hline 11 & Chang [1] & 66 & L-UIQ & 1.1 & $B C S+S L N B$ & Negative $(0 / 3)$ & ND & 12 & Alive and well \\
\hline 12 & Masood [1] & 57 & L-UQs & 3.7 & M+ALND & Negative $(0 / 14)$ & UK & UK & UK \\
\hline 13 & Colella [1] & 79 & $\mathrm{R}$ & 3.0 & M+ALND & Negative $(0 / 8)$ & UK & 18 & Alive and well \\
\hline 14 & \multirow[t]{13}{*}{ Chiang [13] } & 68 & $\mathrm{~L}$ & 0.9 & UK & UK & UK & UK & UK \\
\hline 15 & & 62 & $\mathrm{~L}$ & 0.8 & UK & Negative (0/2) & RT & 77 & Alive and well \\
\hline 16 & & 63 & $\mathrm{~L}$ & 1.2 & UK & UK & UK & UK & UK \\
\hline 17 & & 79 & $\mathrm{R}$ & UK & UK & UK & UK & UK & UK \\
\hline 18 & & 64 & $\mathrm{R}$ & 1.8 & UK & Negative (0/2) & UK & 31 & Alive and well \\
\hline 19 & & 51 & $\mathrm{R}$ & 0.8 & UK & Negative $(0 / 3)$ & ND & 30 & Alive and well \\
\hline 20 & & 64 & $\mathrm{~L}$ & 1.4 & UK & Negative (0/1) & RT & 29 & Alive and well \\
\hline 21 & & 58 & $\mathrm{R}$ & 0.6 & UK & UK & UK & UK & UK \\
\hline 22 & & 66 & $\mathrm{R}$ & 0.9 & UK & Negative (0/3) & CT & 20 & Alive and well \\
\hline 23 & & 65 & $\mathrm{~L}$ & 1.5 & UK & Negative (0/2) & $C T+R T$ & 37 & Alive and well \\
\hline 24 & & 70 & L & 1.3 & UK & Negative (0/2) & UK & 12 & Alive and well \\
\hline 25 & & 65 & $\mathrm{~L}$ & 1.2 & UK & Negative (0/4) & UK & UK & UK \\
\hline 26 & & 65 & L & 0.9 & UK & UK & UK & UK & UK \\
\hline 27 & \multirow{3}{*}{$\begin{array}{c}\text { Bhargava } \\
{[3]}\end{array}$} & 65 & $\mathrm{~L}$ & 0.9 & UK & UK & ND & 19 & Alive and well \\
\hline 28 & & 77 & L-OQs & 1.7 & UK & UK & ND & UK & UK \\
\hline 29 & & 48 & R-UQs & 1.2 & BCS & UK & NAC & 19 & Alive and well \\
\hline 30 & \multirow{13}{*}{$\begin{array}{c}\text { Foschini } \\
\text { [13] }\end{array}$} & 58 & L-LIQ & 1.2 & BCS+SLNB & Negative & ND & 108 & Alive with recurrence \\
\hline 31 & & 80 & R-LOQ & 2.5 & BCS & Positive (1/1) & ND & 120 & Alive and well \\
\hline 32 & & 61 & $\mathrm{R}$ & 2.0 & $B C S+S L N B$ & Negative & ND & 132 & Alive and well \\
\hline 33 & & 62 & L & 1.0 & BCS & UK & ND & 96 & Alive and well \\
\hline 34 & & 51 & L & 2.0 & BCS & UK & ND & UK & UK \\
\hline 35 & & 58 & L & 0.8 & $\mathrm{BCS}+\mathrm{SLNB}$ & Negative & ND & 24 & Alive and well \\
\hline 36 & & 61 & L-IQs & 0.6 & $B C S$ & UK & ND & 124 & Alive and well \\
\hline 37 & & 50 & $\mathrm{R}$ & 0.8 & BCS & UK & $\mathrm{CT}+\mathrm{RT}$ & 84 & Alive and well \\
\hline 38 & & 59 & R-UOQ & 2.5 & $B C S$ & UK & ND & 76 & Alive and well \\
\hline 39 & & 48 & L & 2.2 & BCS & UK & ND & 24 & Alive and well \\
\hline 40 & & 85 & $\mathrm{R}$ & 1.5 & $B C S$ & UK & ND & UK & UK \\
\hline 41 & & 64 & L-LIQ & 2.0 & BCS+ALND & Negative (0/11) & ND & 36 & Alive and well \\
\hline 42 & & 77 & $\mathrm{R}$ & 1.2 & BCS & UK & ND & 24 & Alive and well \\
\hline 43 & \multirow{9}{*}{$\begin{array}{c}\text { Alsadoun } \\
\text { [9] }\end{array}$} & 63 & L & 1.6 & BCS & UK & UK & UK & UK \\
\hline 44 & & 70 & L & 1.1 & BCS & UK & ND & UK & UK \\
\hline 45 & & 72 & $\mathrm{R}$ & 1.0 & BCS & UK & ND & UK & UK \\
\hline 46 & & 64 & L & 1.5 & $B C S$ & UK & UK & UK & UK \\
\hline 47 & & 71 & L & 0.9 & BCS & UK & UK & UK & UK \\
\hline 48 & & 52 & $\mathrm{R}$ & 4.0 & $B C S$ & UK & UK & UK & UK \\
\hline 49 & & 69 & $\mathrm{~L}$ & 1.0 & $\mathrm{BCS}+\mathrm{SLNB}$ & UK & ND & 53 & Alive and well \\
\hline 50 & & 57 & $\mathrm{R}$ & 1.2 & $B C S$ & UK & UK & UK & UK \\
\hline 51 & & 75 & $\mathrm{R}$ & 3.0 & BCS & UK & UK & UK & UK \\
\hline 52 & Gai [1] & 55 & $R-U I Q$ & UK & $M+S L N B$ & Negative & UK & UK & UK \\
\hline 53 & \multirow[t]{8}{*}{ Zhong [8] } & 63 & L & 0.6 & UK & UK & UK & UK & UK \\
\hline 54 & & 63 & $\mathrm{R}$ & 1.0 & UK & UK & UK & UK & UK \\
\hline 55 & & 79 & $\mathrm{R}$ & 1.6 & M & Negative & UK & UK & UK \\
\hline 56 & & 69 & L & 1.2 & UK & UK & UK & UK & UK \\
\hline 57 & & 69 & L & 1.8 & UK & UK & UK & UK & UK \\
\hline 58 & & 71 & $\mathrm{R}$ & 1.7 & UK & UK & UK & UK & UK \\
\hline 59 & & 74 & $\mathrm{R}$ & 0.8 & UK & UK & UK & UK & UK \\
\hline 60 & & 76 & L & 0.7 & UK & UK & UK & UK & UK \\
\hline 61 & Lozada [3] & 60 & UK & 1.1 & UK+SLNB & Negative & UK & UK & UK \\
\hline 62 & & 60 & UK & 2.1 & BCS & Negative & RT & UK & UK \\
\hline 63 & & 67 & UK & 0.6 & UK & UK & UK & UK & UK \\
\hline 64 & Pareja [9] & 67 & UK & 1.0 & UK & UK & UK & UK & UK \\
\hline 65 & & 59 & UK & 1.5 & BCS & Negative & RT & UK & UK \\
\hline 66 & & 64 & UK & 1.2 & BCS & Negative & RT & UK & UK \\
\hline 67 & & 70 & UK & 1.3 & UK & UK & UK & UK & UK \\
\hline 68 & & 67 & UK & 1.7 & UK & Negative & UK & UK & UK \\
\hline 69 & & 60 & UK & 2.6 & UK & Negative & UK & UK & UK \\
\hline 70 & & 47 & UK & 1.3 & UK & UK & UK & UK & UK \\
\hline 71 & & 80 & UK & 0.6 & UK & UK & UK & UK & UK \\
\hline 72 & & 46 & UK & 0.6 & UK & UK & UK & UK & UK \\
\hline 73 & Haefliger [1] & 60 & R-LIQ & 0.8 & $\mathrm{BCS}+\mathrm{SLNB}$ & Negative & UK & 8 & Alive and well \\
\hline pres & 7hang (11) & 45 & L-UOQ & 10 & $B C S+S L N B$ & Neaative $(0 / 6)$ & $C T+R T$ & 12 & Alive and we \\
\hline
\end{tabular}


Table S2 Immunohistochemical and hotspot gene mutations information of patients

\begin{tabular}{|c|c|c|c|c|c|c|c|c|c|c|c|}
\hline Case No. & ER & PR & AR & HER-2 & CK5/6 & $\mathrm{p} 63$ & GCDFP-15 & TFF-1 & Thy & IDH2 & PIK3CA \\
\hline 1 & - & - & + & ND & ND & ND & + & - & - & ND & ND \\
\hline 2 & - & - & - & ND & ND & ND & - & - & - & ND & ND \\
\hline 3 & - & - & - & ND & ND & ND & - & - & - & ND & ND \\
\hline 4 & - & - & - & ND & ND & ND & - & - & - & ND & ND \\
\hline 5 & ND & ND & ND & ND & ND & ND & ND & ND & ND & ND & ND \\
\hline 6 & + & + & + & - & ND & ND & + & - & - & ND & ND \\
\hline 7 & - & - & - & ND & ND & $+/-$ & + & - & - & ND & ND \\
\hline 8 & ++ & ++ & - & ND & ND & - & +++ & - & - & ND & ND \\
\hline 9 & $+/-$ & - & ND & ND & ND & ND & - & - & - & ND & ND \\
\hline 10 & ++ & ++ & - & ND & ND & + & - & - & - & ND & ND \\
\hline 11 & + & - & - & - & ND & - & + & - & ND & ND & ND \\
\hline 12 & + & + & ND & - & ND & ND & ND & - & - & ND & ND \\
\hline 13 & - & - & ND & - & ND & ND & + & - & - & ND & ND \\
\hline 14 & - & - & ND & ND & + & - & + & - & ND & - & + \\
\hline 15 & - & - & - & - & + & - & - & - & - & + & + \\
\hline 16 & + & + & - & ND & + & - & + & ND & ND & + & + \\
\hline 17 & - & - & - & ND & + & - & + & - & - & + & + \\
\hline 18 & - & - & - & - & + & - & + & - & - & + & + \\
\hline 19 & + & + & - & - & + & - & + & - & ND & - & + \\
\hline 20 & + & - & - & - & + & - & - & - & - & + & - \\
\hline 21 & - & - & - & - & - & - & - & - & - & + & + \\
\hline 22 & - & - & - & - & + & - & + & - & - & + & + \\
\hline 23 & + & - & ND & - & + & - & - & - & - & + & + \\
\hline 24 & + & - & - & - & + & - & + & - & - & - & + \\
\hline 25 & - & - & - & - & + & - & - & - & - & + & - \\
\hline 26 & - & - & + & - & + & - & + & - & - & + & + \\
\hline 27 & - & ND & ND & ND & + & - & ND & ND & ND & + & - \\
\hline 28 & + & ND & ND & ND & + & - & + & - & - & - & - \\
\hline 29 & + & ND & + & ND & + & - & ND & ND & ND & + & + \\
\hline 30 & - & - & - & - & + & - & - & - & - & + & - \\
\hline 31 & - & - & - & - & + & - & - & - & - & ND & ND \\
\hline 32 & + & - & - & - & - & - & - & - & - & ND & ND \\
\hline 33 & - & - & ND & - & ND & - & ND & - & - & ND & ND \\
\hline 34 & - & - & ND & - & - & - & ND & - & ND & ND & ND \\
\hline 35 & + & + & - & - & ND & - & + & - & - & ND & ND \\
\hline 36 & - & - & - & - & + & ND & + & - & - & ND & ND \\
\hline 37 & - & - & - & - & - & - & - & - & - & ND & ND \\
\hline 38 & - & - & - & - & + & - & - & - & - & + & + \\
\hline 39 & - & - & - & - & + & - & + & - & - & ND & ND \\
\hline 40 & - & - & - & - & + & - & - & - & - & + & + \\
\hline 41 & - & - & - & - & ND & - & + & - & - & ND & ND \\
\hline 42 & + & + & - & - & + & - & + & - & - & ND & ND \\
\hline 43 & + & + & + & - & + & - & + & - & ND & - & ND \\
\hline 44 & - & - & + & - & + & - & + & - & ND & + & ND \\
\hline 45 & + & - & + & - & + & - & + & - & ND & + & ND \\
\hline 46 & - & - & - & - & + & - & - & - & ND & + & ND \\
\hline 47 & - & - & - & - & + & - & + & - & ND & + & ND \\
\hline 48 & + & + & + & - & + & - & + & - & ND & + & ND \\
\hline 49 & - & - & - & - & + & - & - & - & ND & + & ND \\
\hline 50 & + & - & + & - & - & - & + & - & ND & + & $\mathrm{ND}$ \\
\hline 51 & + & + & - & - & + & - & + & - & ND & - & ND \\
\hline 52 & - & - & ND & - & + & - & - & - & - & ND & ND \\
\hline 53 & - & - & ND & - & ND & + & ND & ND & ND & + & + \\
\hline 54 & - & - & - & - & + & - & ND & - & ND & + & - \\
\hline 55 & ND & ND & - & ND & + & - & ND & - & ND & + & + \\
\hline 56 & + & - & ND & - & ND & ND & ND & ND & ND & + & + \\
\hline 57 & - & - & ND & - & ND & ND & + & - & ND & + & + \\
\hline 58 & - & - & ND & - & ND & ND & - & - & ND & + & + \\
\hline 59 & - & - & ND & ND & ND & ND & ND & ND & ND & ND & ND \\
\hline 60 & + & + & ND & ND & ND & - & ND & ND & ND & + & + \\
\hline 61 & - & - & ND & - & + & - & ND & ND & ND & + & + \\
\hline 62 & - & - & ND & - & + & - & ND & ND & ND & + & + \\
\hline 63 & - & - & ND & - & + & - & ND & ND & ND & + & - \\
\hline 64 & - & ND & + & ND & + & - & ND & ND & ND & + & - \\
\hline 65 & + & ND & + & ND & ND & - & ND & ND & ND & + & - \\
\hline 66 & + & ND & + & ND & + & - & ND & ND & ND & + & - \\
\hline 67 & - & ND & + & ND & + & - & ND & ND & ND & + & + \\
\hline 68 & - & ND & - & ND & + & - & ND & ND & ND & + & + \\
\hline 69 & + & ND & + & ND & + & - & ND & ND & ND & + & + \\
\hline 70 & - & ND & + & ND & + & - & ND & ND & ND & + & - \\
\hline 71 & + & ND & + & ND & + & - & ND & ND & ND & + & - \\
\hline 72 & - & ND & ND & ND & + & - & ND & ND & ND & + & - \\
\hline 73 & - & - & - & - & + & - & ND & - & ND & + & + \\
\hline present & - & - & + & - & + & - & + & - & - & + & + \\
\hline
\end{tabular}

